GENOME METHODS

\title{
A Novel Method for Real Time Quantitative RT-PCR
}

\author{
Ursula E.M. Gibson, ${ }^{1}$ Christian A. Heid, and P. Mickey Williams
}

\author{
Genentech, Inc., South San Francisco, California 94080-4990
}

\begin{abstract}
A novel approach to quantitative reverse transcriptase polymerase chain reaction (QC RT-PCR) using real time detection and the $5^{\prime}$ nuclease assay has been developed. Cystic fibrosis transmembrane transductance regulator (CFTR) target mRNA is reverse transcribed, amplified, detected, and quantitated in real time. A fluorogenic probe was designed to detect the CFTR amplicon. Relative increase in 6-carboxy-fluorescein reporter fluorescent emission is monitored during PCR amplification using an analytical thermal cycler. An internal control template containing the same primer sequences as the CFTR amplicon, but a different internal sequence, has been designed as a control. An internal control probe with a reporter fluorescent dye tetrachloro-6-carboxy-fluorescein was designed to hybridize to the internal control amplicon. The internal control template is placed in each reaction tube and is used for quantitative analysis of the CFTR mRNA. This method provides a convenient and high-throughput format for QC RT-PCR.
\end{abstract}

The polymerase chain reaction (PCR) is a rapid and powerful technique for the in vitro amplification of DNA (Mullis et al. 1986; Gibbs 1990). Quantitative PCR (QC PCR) has been used to quantitate small amounts of DNA and QC RTPCR has been used to measure mRNA. QC PCR and QC RT-PCR methods use an internal control that is coamplified with the target sequence (Becker-Andre 1991; Ferre 1992; Siebert and Larrick 1992; Piatak et al. 1993; McCulloch et al. 1995; Raeymaekers 1995). The internal control can be designed several ways: scrambling of the internal sequence, mutation of the target amplicon, deletion or insertion of sequences into the target amplicon, or splicing of the target primer sequences onto a nonhomologous DNA sequence. As a general rule, the target and control should use the same primers, contain similar guanine + cytosine $(\mathrm{G}+\mathrm{C})$ content, and be of equal or similar length. Once a control has been designed, it is important to validate the internal control. Validation requires demonstration that the competitive control amplify with equal efficiency and achieve plateau simultaneously with the target (Raeymaekers 1995). Although absolute quantitation requires the accurate determination of internal control concentration, relative quantitation can be established easily with a validated internal control. Quantitation of target and

'Corresponding author.

E-MAIL mickey@gene.com; FAX (415) 225-1411. coamplified internal control generally is done by quantitating the intensity of ethidium bromide staining of the PCR products on an agarose or acrylamide gel, a time-consuming and potentially inaccurate approach.

The 5 ' nuclease assay for detecting PCR products (Holland et al. 1991; Lee et al. 1993; Livak et al. 1995a,b) uses a nonextendable oligonucleotide hybridization probe. The probe is labeled with a reporter fluorescent dye [FAM (6-carboxyfluorescein)] at the 5 ' end and a quencherfluorescent dye [TAMRA (6-carboxy-tetramethylrhodamine)] at the $3^{\prime}$ end. When the probe is intact, the reporter dye emission is quenched owing to the physical proximity of the reporter and quencher fluorescent dyes. During the extension phase of the PCR cycle, however, the nucleolytic activity of the DNA polymerase cleaves the hybridization probe and releases the reporter dye from the probe. The resulting relative increase in reporter fluorescent dye emission is monitored in real time during PCR amplification using a sequence detector, the 7700 Sequence Detector (PE Applied BioSystems, Foster City, CA). The sequence detector is a combination thermal cycler, laser, and detection and software system that automates 5 ' nuclease-based detection and quantitation of nucleic acid sequences. Fluorescence intensity produced during PCR amplifications in each of the 96 tubes is monitored in real time. A computer algorithm compares the amount of reporter dye emission $(\mathrm{R})$ with the quenching dye 
emission (Q) every 8.5 seconds during the PCR amplification, generating a $\Delta \mathrm{Rn}$ value $(\mathrm{R} / \mathrm{Q})$ (also called $\Delta \mathrm{RQ}$ ). The $\Delta \mathrm{Rn}$ value reflects the amount of hybridization probe that has been degraded. The algorithm fits an exponential function to the mean $\Delta R n$ values of the last three data points of every PCR extension cycle, generating an amplification plot. A relative fluorescent emission threshold is set based on the baseline of the $\Delta \mathrm{Rn}$ during the first 10-15 cycles (Heid et al., this issue). The algorithm calculates the cycle at which each PCR amplification reaches a significant (i.e. usually 10 times the standard deviation of the baseline) threshold $\left(\mathrm{C}_{\mathrm{T}}\right)$. In the accompanying manuscript (Heid et al., this issue), it was demonstrated that the calculated $\mathrm{C}_{\mathrm{T}}$ value is proportional to the number of target copies present in the sample. Thus, the $C_{T}$ value is a quantitative measurement of the copies of the target found in any sample.

The use of a charge coupled device (CCD) camera permits the detection of a wide spectrum of emission wavelengths. By using target and control probes containing different reporter fluorescent dyes [FAM, JOE (2,7-dimethoxy-4,5dichloro-6-carboxy-fluorescein), or TET (tetrachloro-6-carboxy-fluorescein)], it is possible to detect simultaneously both target and control RNA in a single reaction tube. However, in practice this approach is limited to concentrations of target and internal control RNA or DNA that are within 1000-fold of each other. This limitation is attributable, at least partially, to the overlapping spectra of the reporter dyes available. To develop an assay with a large dynamic range of input target quantitation, duplicate reactions containing both target and internal control RNA were set up. Target probe (prA) was added to one reaction and internal control probe (prB) to the other reaction. With this approach accurate detection of low concentrations of target mRNA without interference from internal control fluorescence was possible.

This report describes a quantitative RT-PCR assay, that was developed to support a gene therapy project aimed at treating cystic fibrosis. The target for this assay was the cystic fibrosis transmembrane receptor (CFTR) mRNA, and the internal control was constructed by adding the CFTR forward and reverse primers to a sequence of the pGEM-3Z plasmid. The pGEM-3Z plasmid sequence was of similar length and contained similar G + C nucleotide content to the CFTR amplification product.

\section{RESULTS}

\section{Amplification Plots and Cycle Threshold, $C_{T}$}

During the PCR amplification, the nucleolytic activity of the DNA polymerase ( $T f l$ ) cleaves the target specific hybridization probe and releases the reporter dye, FAM or TET, from the probe. The increase in fluorescence emission of the reporter dye is proportional to the amount of PCR product accumulated, which in turn is proportional to the starting target concentration (Heid et al., this issue). Fluorescence emission is monitored, in real time using a sequence detector. The emission intensity of the quencher dye, TAMRA, which remains relatively constant during amplification (Livak et al. 1995a), was used as an internal control to normalize fluorescence emission and calculate the $\Delta \mathrm{Rn}$ (reporter dye emission/ quencher dye emission). $\Delta \mathrm{Rn}$ is the fluorescence signal increase due to template amplification and is calculated by subtracting the background fluorescence: $\Delta R n=\left(R n^{+}\right)-\left(R n^{-}\right)$, where $R n^{+}=($emission intensity of reporter)/(emission intensity of quencher of PCR with template) and $\mathrm{Rn}^{-}=$(emission intensity of reporter)/(emission intensity of quencher of PCR without template).

Figure 1 shows amplification plots of twofold serial dilutions of total RNA from adeno CFTRinfected T84 cells. For this experiment total RNA was serially diluted from a starting concentration that contained $\sim 2 \times 10^{7}$ copies of adeno CFTR mRNA down to a concentration containing $\sim 1000$ copies (the mRNA copy values were deter-

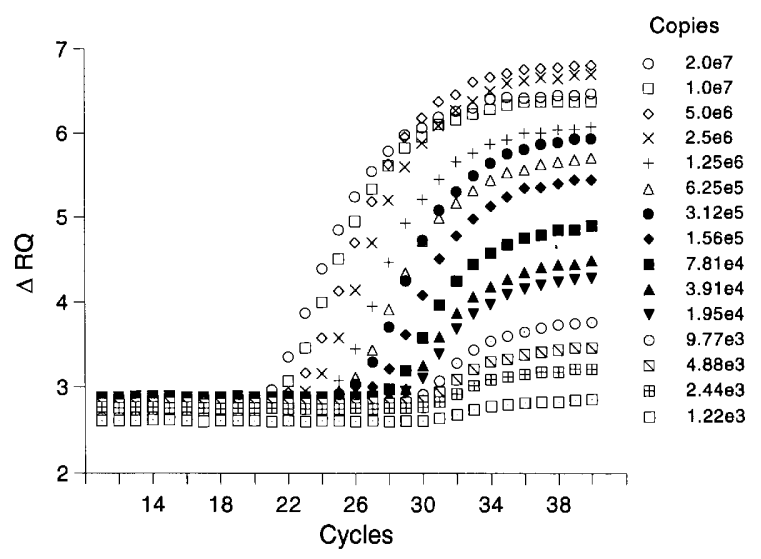

Figure 1 Amplification plots of adeno-CFTR target mRNA. Twofold serial dilutions of adeno-CFTR target mRNA were reverse transcribed and amplified using the $5^{\prime}$ nuclease assay and the sequence detector. For each dilution the $\Delta \mathrm{Rn}$ is plotted against the cycle number. 


\section{A NOVEL METHOD FOR REAL IIME QUANTIIAIIVE RI-PCR}

mined comparing the T84 cell total RNA with a known amount of internal control RNA copies). The dilutions were then reverse transcribed and amplified using RT-PCR. The change in $\Delta \mathrm{Rn}$ is proportional to the change in concentration of the amplified target, so that dilutions of target require additional PCR cycles to raise the $\Delta R n$ above the threshold value, $C_{T}$.

\section{Colinearity of Dilution of Target CFTR mRNA and Internal Control RNA}

Colinearity of dilution was determined by making serial twofold dilutions of both adeno CFTR internal control and total cell RNA containing the adeno CFTR target mRNA. The range of internal control dilutions covers 6.5 logs and the range of target covers 4 logs of input molecules. Both target and internal control dilutions were reverse transcribed, amplified as described in Methods, and the $\mathrm{C}_{\mathrm{T}}$ values were calculated and plotted against the relative amount of internal control RNA. Each point of the curve (Fig. 2) represents the mean of the three separate RT-PCR amplifications depicted with error bars (too small to be visible in the graph) representing one standard deviation and shows the $\mathrm{C}_{\mathrm{T}}$ value increasing by approximately one for each twofold dilution. Figure 2 shows that both target adeno CFTR mRNA and internal control adeno CFTR RNA amplify linearly and that amplification efficiencies

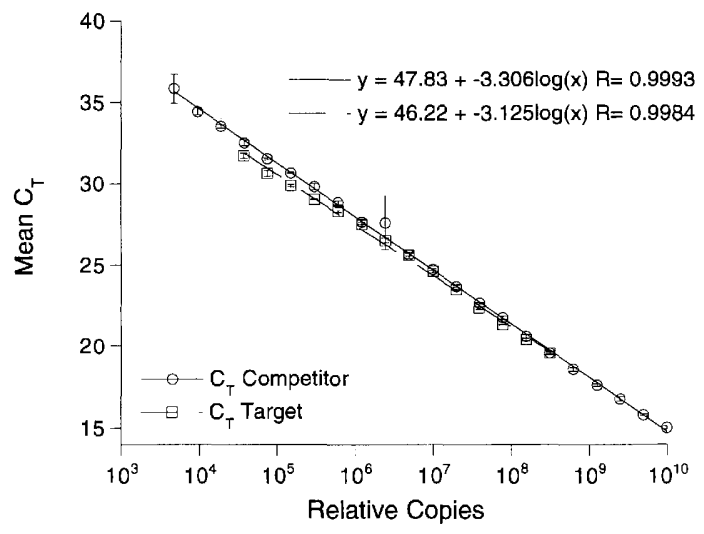

Figure 2 Colinearity of dilution and assay range of adeno CFTR target and internal control RNA. Twofold serial dilutions of target and internal control RNA were prepared in triplicate, reverse transcribed, and amplified using the sequence detector. Mean $C_{T}$ values are plotted against relative copy number, with error bars representing one standard deviation. of target and internal control are the same over the range tested.

\section{Real Time QC RT-PCR}

A known amount of an internal control was added for reverse transcription and amplification. By amplifying both internal control and target in the same tube, identical conditions for each are assured. For this purpose, a mixture that contained all the reagents required for reverse transcription and amplification (RT-PCR), primers P1 and P2, and target samples (containing unknown amounts of target CFTR mRNA), was prepared. This mixture was used to generate two sets of tubes, set I and set II, containing eight serial dilutions of a known amount of internal control RNA. To detect the amount of the CFTR mRNA RT-PCR amplicon, the CFTR target hybridization probe was added to set I tubes and the internal control hybridization probe was added to set II tubes. Both sets of tubes were subjected to RTPCR amplification using the sequence detector. Because the corresponding tubes from sets I and II contained identical concentrations of target and internal control RNA, reverse transcription and amplification for both sets of tubes were assumed to be identical. However, because the set I tubes contained the target probe, its reporter fluorescent emission was attributable entirely to amplification of target and unaffected by the concentration of internal control RNA. The reporter fluorescence in the tubes containing internal control probe (set II) was attributable entirely to internal control amplification. By plotting the mean $\mathrm{C}_{\mathrm{T}}$ values of internal control and target against the known internal control copy number, the number of unknown target molecules could be determined from the theoretical equivalence point, where $\mathrm{C}_{\mathrm{T}}$ of target equals $\mathrm{C}_{\mathrm{T}}$ of internal control (i.e. where the lines intersect; see Figs. $3 \mathrm{~A}, \mathrm{~B})$. In this experiment, two different concentrations of target, either a 1:25 dilution (Fig. 3A) or a 1:125 dilution (Fig. 3B) of the total RNA preparation from adenovirus-infected cells, were used with twofold serial dilutions of internal control. As shown in Figure $3 \mathrm{~A}$, the mean $\mathrm{C}_{\mathrm{T}}$ of the internal control dilution series intersected the mean $\mathrm{C}_{\mathrm{T}}$ plot of the 1:25 dilution of target at an estimated $6.7 \times 10^{6}$ copies of target $\mathrm{mRNA} / \mathrm{ml}$, whereas the $1: 125$ dilution of target indicated $9.6 \times 10^{5}$ copies of target mRNA/ml (Fig. 3B). Multiplication by their respective dilution factors gave $1.7 \times 10^{8}$ copies of $\mathrm{mRNA} / \mathrm{ml}$ for the $1: 25$ 
GIBSON ET AL.

A

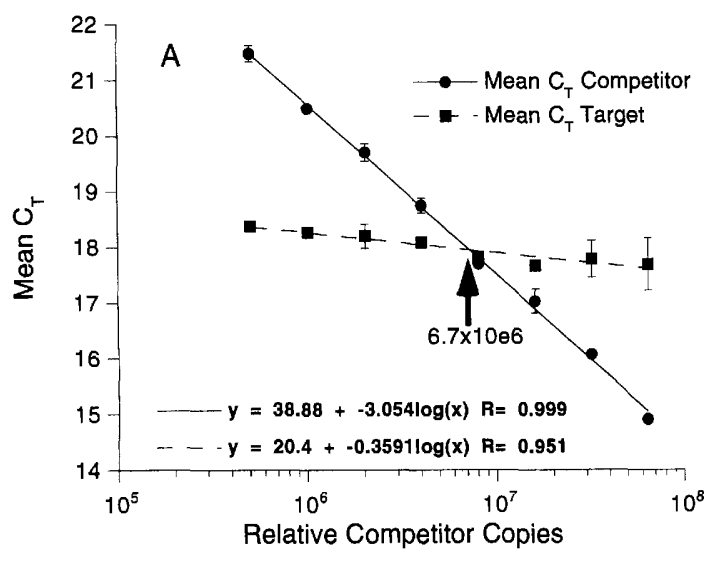

B

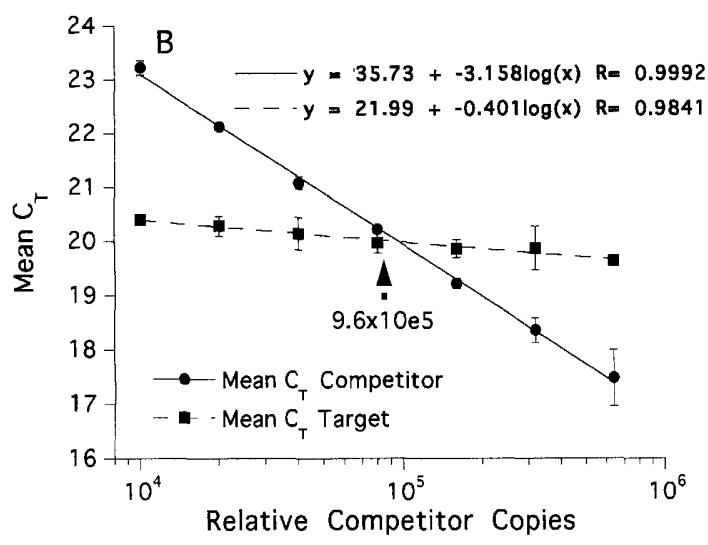

Figure 3 QC RT-PCR. Duplicate sets of tubes containing fixed concentrations of adeno CFTR target were co-amplified with twofold serial dilutions of internal control RNA $(n=3)$. Target hybridization probe was added to the first set of tubes, while internal control hybridization probe was added to the second set of tubes. Mean $C_{T}$ values of target and internal control are plotted against the relative copy number of internal control in each reaction tube. Target copy number is shown at the intersection of the two lines, and $C_{T}$ of target equals $C_{T}$ of internal control, and is multiplied by the respective target dilution to obtain the initial copy number for each microliter of target mRNA. (A) 1:25 dilution of target RNA; (B) 1:125 dilution of target RNA.

dilution of target and $1.2 \times 10^{8}$ copies of target/ $\mathrm{ml}$ for the 1:125 dilution of target, with a mean of $1.45 \times 10^{8}$ copies of target $\mathrm{mRNA} / \mathrm{ml}$ stock solution.

Intra-assay and Interassay Precision

To determine precision of the assay, 10 replicates of each dilution of adeno CFTR target mRNA and internal control RNA were reverse transcribed and amplified on three separate days as described. The mean $\mathrm{C}_{\mathrm{T}}$ values, standard deviation (s.D.) and the coefficient of variation (CV) were calculated for each day to obtain intra-assay precision. Mean $\mathrm{C}_{\mathrm{T}}$ values of target were found to range from 29.3 to 29.6 with an intra-assay precision of target amplification from $0.4 \%$ to $1.3 \%$ CV (s.D. 0.092 to 0.372 ). Mean internal control $\mathrm{C}_{\mathrm{T}}$ values ranged from 17.4 to 18.3 and precision of amplification ranged from 0.6 to $1.7 \%$ (s.D. 0.116 to 0.289 ). The interassay precision of amplification for the three days $(n=30)$ was also calculated and found to be $0.5 \%$ for the target and $2.6 \%$ for the internal control.

\section{DISCUSSION}

A new quantitative RT-PCR method, using the fluorescent hybridization probes and a sequence detector has been developed. This approach minimizes variable results caused by potential differences in the efficiency of reverse transcription and amplification because both target mRNA and internal control RNA are added to the same tube. Any amplification inhibitors present in a sample will affect amplification efficiency of both the target mRNA and the internal control RNA. Furthermore, only one set of primers is used to transcribe and amplify both target mRNA and internal control RNA, but different hybridization probes are used to ensure further the accuracy of the assay. Duplicate reactions, one containing the target mRNA probe and the other containing the internal control RNA probe, were prepared. This approach was used to enhance the dynamic range of the assay. Because specific hybridization of both primers and probe is necessary to generate a signal, the assay is both sensitive and specific. Amplification of DNA present in the total RNA preparation is avoided by using an exon/ intron junction spanning forward primer, in which the 5' end of the primer is complementary to the $3^{\prime}$ end sequences of one exon, and the $3^{\prime}$ end of the primer complimentary to the $5^{\prime}$ sequences of the next exon.

Existing methods for quantitation of RT-PCR amplifications have been labor intensive, requiring each sample to be separated by gel electrophoresis, followed by quantitation of bands by ethidium bromide staining or isotopic labeling of the PCR products. One major advantage of the assay described above is the increased ease and 
A NOVEL METHOD FOR REAL TIME QUANTITATIVE RT-PCR

rapidity of sample analysis, allowing higher sample throughput. By using real time QC RTPCR, samples can be reverse transcribed, amplified, and quantitated in one tube, without any further downstream processing. Currently, up to 96 reactions can be analyzed in $-3.5 \mathrm{hr}$ using this assay format. Another advantage is that the $C_{T}$ value, used for quantitation, is measured during a period when the PCR amplification is still in the log phase of amplicon accumulation. This circumvents many of the problems associated with quantitation in the plateau stage of a PCR amplification (Raeymaekers 1995). In addition, the elimination of post-PCR sample manipulations decreases the potential of laboratory nucleic acid contamination. Furthermore, well-to-well variations of fluorescence measurement can be normalized to the quenching fluorescent dye, TAMRA, because the emission intensity of TAMRA changes very little during the RT-PCR.

Currently each assay sample is analyzed in two different RT-PCR tubes: one containing the target probe and the other containing the internal control probe. Using this assay, a dynamic range of over $10^{6.5}$ target molecules was obtained. Assay throughput could be increased by adding both probes to the same RT-PCR tube. Reporter dyes with less spectral overlap compared to FAM and TET may be useful for large dynamic range assays in a single tube.

Precision of the QC RT-PCR assay was found to be excellent, with intra-assay CVs of $<2 \%$ and interassay CVs of $<3 \%$. Quantitation of both target and internal control were shown to be linear over six logs and the assay can measure as little as 1000 copies of mRNA per tube. Recent results indicate a minimum detection and quantitation of 400 RNA molecules is possible (data not shown).

A real time PCR assay using a constant amount of input DNA for each assay sample and a normalization gene to normalize for any minor variations of input DNA concentration, has been developed (Heid et al., this issue). Several quantitative RT-PCR assays which use housekeeping genes as an internal control have also been developed in our laboratory (data not shown). These approaches eliminate the need to design individual internal control templates for each gene in a multigene expression assay.

In conclusion, this method for the quantitation of mRNA is sensitive, accurate, and can be used to quantitate large numbers of samples in a relatively short time. The use of two different fluorescent hybridization probes and a known concentration of internal control RNA allows the initial mRNA copy number of an unknown target to be calculated.

\section{METHODS}

\section{Oligonucleotides}

Table 1 shows the nucleotide sequences for the oligonucleotide hybridization probes and primers used. CFTR primers and probes were designed using the Oligo Version 4.0, National Biosciences, program. The forward primer (P1) was designed to span an exon/intron junction to avoid amplification of DNA sequences, whereas the reverse CFTR primer (P2) was complimentary to an exon. The CFTR target probe (prA) was labeled with FAM and the internal control probe (prB) with TET at the 5 ' end. Both probes were labeled with the quencher fluor TAMRA at the $3^{\prime}$ end followed by the phosphorylation site $\mathrm{p}$.

Oligonucleotide hybridization probes (see Table 1) were obtained from Applied Biosystems Division, PerkinElmer (Foster City, CA). Primers were obtained from the Oligo Synthesis group, Genentech, Inc. (South San Francisco, CA).

\section{Internal RNA Control}

To construct the RNA internal control, a second set of primers (P3 and P4) were designed by appending the CFTR $\mathrm{P} 1$ and $\mathrm{P} 2$ primers to forward and reverse primers complementary to a pGEM-3Z plasmid (Clontech, Palo Alto, CA) sequence. The particular pGEM-3Z sequence was chosen because it contained similar $\mathrm{G}+\mathrm{C}$ nucleotide content and was similar in size compared to the CFTR amplicon. Amplification of the pGEM-3Z plasmid with these primers yielded a DNA product consisting of an internal pGEM-3Z sequence with CFTR primer sequences at each $5^{\prime}$ end [CFTR(P1)/pGEM-3Z/CFTR(P2)]. A third forward primer (P5) was constructed by appending the T7 phage promoter sequence, followed by an additional six bases (Stoflet et al. 1988), to the $5^{\prime}$ end of the forward CFTR primer. Amplification of the CFTR(P1)/pGEM-3Z/CFTR(P2) DNA with the T7-containing forward CFTR primer (P5) and the reverse CFTR primer (P2) yielded an amplification product suitable for transcription, with the $\mathrm{T} 7$ promoter at the $5^{\prime}$ end of the sense strand [T7/CFTR(P1)/pGEM-3Z/CFTR(P2)]. Each of the above PCR products was gel purified, using the QIAEX Gel Extraction Kit, (QIAGEN, Chatsworth, CA).

\section{Transcription}

Internal control DNA was transcribed using the T7 MEGAscript in vitro Transcription Kit (Ambion, Austin, TX) for large scale synthesis of RNA. Transcription was accomplished by following the Ambion protocol, and extending the incubation time at $37^{\circ} \mathrm{C}$ for $7 \mathrm{hr}$. After incubation the DNA was degraded by the addition of RNase-free DNase I, and the reaction was stopped, as described in the Ambion method. The RNA was recovered by extraction with phenol/ $\mathrm{CHCl}_{3}$, followed by precipitation of the RNAcontaining aqueous phase with one volume of isopropa- 
Table 1. Primers and Probes

\begin{tabular}{|c|c|c|c|}
\hline & Primer/probe & & $\begin{array}{l}\text { Base } \\
\text { pairs }\end{array}$ \\
\hline P1 & $\begin{array}{l}\text { CFTR primer, } \\
\text { forward }\end{array}$ & 5'-CCGTGCCAAGAGTGACGTGTC-3' & 21 \\
\hline P2 & $\begin{array}{l}\text { CFTR primer, } \\
\text { reverse }\end{array}$ & 5'-AAGCCAGCTCTCTATCCСАТТСТC-3' & 24 \\
\hline P3 & $\begin{array}{l}\text { CFTR-pGEM-3Z } \\
\text { primer } \\
\text { forward }\end{array}$ & 5'-CCGTGCCAAGAGTGACGTGTCCTATCGTCTTGAGTCCAACC-3' & 41 \\
\hline P4 & $\begin{array}{l}\text { CFTR-pGEM-3Z } \\
\text { primer, } \\
\text { reverse }\end{array}$ & 5'-AAGCСАGСТСТСТАТСССАТТСТСАТСССТТАAСGTGAGTTITC-3' & 44 \\
\hline P5 & $\begin{array}{l}\text { T7-CFTR primer, } \\
\text { forward }\end{array}$ & $\begin{array}{l}\text { 5'-GGATCCTAATACGACTCACTATAGGGAGGCCGTGCCAAGAGTGA } \\
\text { CGTGTC-3' }\end{array}$ & 50 \\
\hline pr6 & CFTR probe & 5'(FAM)-TGGACCAGACCAATTTTGAGGAAAGGA-(TAMRA)p3' & 27 \\
\hline pr7 & $\begin{array}{l}\text { Competitor } \\
\text { (pGEM-3Z) } \\
\text { probe }\end{array}$ & 5'(TET)-TGGTATCTGCGCTCTGCTGAAGCC-(TAMRA)p3' & 24 \\
\hline
\end{tabular}

nol. The RNA precipitate was washed two times in $75 \%$ ethanol, dried briefly in air, and resuspended in RNase-free TE buffer $(10 \mathrm{~mm}$ Tris- $\mathrm{HCl}$ at $\mathrm{pH} 7.6,1 \mathrm{~mm}$ EDTA at $\mathrm{pH}$ 8.0). The concentration of the 319-bp internal control RNA was determined by ultraviolet spectroscopy.

\section{PCR}

PCR reagents were obtained from Boehringer Mannheim (Indianapolis, IN). The following conditions were used for PCR unless otherwise specified: Buffer composed of $10 \mathrm{~mm}$ Tris- $\mathrm{HCl}$ (pH 8.3), $50 \mathrm{mM} \mathrm{KCl}, 1.5 \mathrm{mM} \mathrm{MgCl}_{2}$, dNTPs at 0.2 $\mathrm{mm}$, forward and reverse primers at $500 \mathrm{nM}$, and Taq polymerase at $5 \mathrm{U} / 100 \mu \mathrm{L}$. Cycle parameters were $94^{\circ} \mathrm{C}$ for 2 min, followed by 40 cycles of $94^{\circ} \mathrm{C}$ for $30 \mathrm{sec}, 60^{\circ} \mathrm{C}$ for 30 sec, and $72^{\circ} \mathrm{C}$ for $1 \mathrm{~min}$, with a final extension at $72^{\circ} \mathrm{C}$ for $7 \mathrm{~min}$.

\section{Cell Culture}

Human colon carcinoma T84 cells (ATCC CCL 248) were grown in a 1:1 mixture of Ham's F12 medium and Dulbecco's modified Eagle's medium with $6 \%$ newborn calf serum (Gibco) and gentamicin. For adenovirus infection, the cells were seeded in growth medium in $25 \mathrm{cc}$ flasks and incubated overnight in a humidified atmosphere of $95 \%$ air $/ 5 \% \mathrm{CO}_{2}$ at $37^{\circ} \mathrm{C}$. The cells were washed with phosphate-buffered saline (PBS) and infected with the replication-deficient adenovirus containing the coding sequence of the CFTR gene at an approximate multiplicity of infection of 100 and incubated at $37^{\circ} \mathrm{C}$ overnight. The incubation medium was as described above, but with $2 \%$ of newborn calf serum.

\section{Total RNA Extraction}

RNAzol B (Tel-Test, Inc., Friendswood, TX) was used to extract total RNA from T84 cells infected with a recombinant, replication-deficient adenoviral vector containing the human CFTR cDNA. Cell monolayers were washed with PBS, and $1 \mathrm{ml}$ of RNAzol/ $10^{6}$ cells with 4 units of RNase inhibitor (5 Prime $\rightarrow 3$ Prime, Inc., Boulder, CO) was added. The cells were solubilized by passing the lysate through the pipette a few times. One-tenth volume of chloroform was added, and the sample was capped and shaken vigorously, followed by a $5 \mathrm{~min}$ incubation on ice. The suspension was centrifuged at $12,000 \mathrm{~g}$ at $4^{\circ} \mathrm{C}$ for 15 min. The RNA in the aqueous phase was transferred to a clean tube. The RNA was precipitated with an equal volume of isopropanol, stored for $15 \mathrm{~min}$ at $4^{\circ} \mathrm{C}$ and pelleted by centrifugation at $8000 \mathrm{~g}$ for $8 \mathrm{~min}$ at $4^{\circ} \mathrm{C}$. The RNA pellet was washed twice with $75 \%$ ethanol, air dried, and resuspended in TE with 4 units/ml RNase inhibitor.

\section{QC RT-PCR}

The Access RT-PCR System (Promega, Madison, WI) was used to reverse transcribe and amplify both target and internal control. The reaction master mix was prepared according to the manufacture's protocol to give final concentrations of $1 \times \mathrm{AMV} / \mathrm{T} f \mathrm{l}$ reaction buffer, $0.2 \mathrm{mM}$ dNTPs, $1 \mathrm{mM} \mathrm{MgSO}_{4}, 0.1 \mathrm{U} / \mathrm{ml}$ AMV Reverse Transcriptase, 0.1 U/ $\mu l$ Tfl DNA Polymerase, and 250 nM CFTR primers P1 and P2. Target RNA (total RNA extracted from the adenovirus-infected cells) was added to the master mix. The master mix was then split into parts I and II and target hybridization probe was added to master mix I, and internal control hybridization probe was added to master mix II, to 


\section{A NOVEL METHOD FOR REAL TIME QUANTITATIVE RT-PCR}

give final probe concentrations of $200 \mathrm{nM}$. Each master mix was transferred to a set of thermocycler tubes and twofold serial dilutions of internal control RNA were added to triplicate tubes of each master mix. Target and internal control were reverse transcribed at $48^{\circ} \mathrm{C}$ for 45 min, followed by 40 cycles of amplification at $95^{\circ} \mathrm{C}$ for 30 $\mathrm{sec}, 55^{\circ} \mathrm{C}$ for $45 \mathrm{sec}$, and $68^{\circ} \mathrm{C}$ for $1 \mathrm{~min}$, using the ATC.

RT-PCR amplifications were also examined by agarose gel electrophoresis. After ethidium bromide staining, bands were visible only at the expected molecular weights for the CFTR mRNA and internal control products.

\section{ACKNOWLEDGMENTS}

We thank Ayly Tucker for the adeno CFTR primer design and the Genentech DNA Synthesis group for the primer synthesis. We also thank Junko Stevens, PE Applied Biosystems, for instructing us in the use of the ATC Model 7700 Sequence Detector, and R.G. Crystal, MD for the kind gift of $\mathrm{Ad}_{\mathrm{GV}}$ CFTR.10 virus.

The publication costs of this article were defrayed in part by payment of page charges. This article must therefore be hereby marked "advertisement" in accordance with 18 USC section 1734 solely to indicate this fact.

\section{REFERENCES}

Becker-Andre, M. 1991. Quantitative evaluation of mRNA levels. Meth. Molec. Cell. Biol. 2: 189-201.

Ferre, F. 1992. Quantitative or semi-quantitative PCR: reality versus myth. PCR Methods Applic. 2: 1-9.

Gibbs, R.A. 1990. DNA amplification by the polymerase chain reaction. Anal. Chem. 62: 1202-1214.

Heid, C., J. Stevens, K. Livak, and P.M. Williams. 1996. Real time quantitative PCR. Genome Res. (this issue).

Holland, P.M., R.D. Abramson, R. Watson, and D.H. Gelfand. 1991. Detection of specific polymerase chain reaction product by utilizing the 5 ' $-3^{\prime}$ exonuclease activity of Thermus aquaticus DNA polymerase. Proc. Natl. Acad. Sci. 88: 7276-7280.

Lee, L.G., C.R. Connell, and W. Bloch. 1993. Allelic discrimination by nick-translation PCR with fluorogenic probes. Nucleic Acids Res. 21: 3761-3766.

Livak, K.J., S.J. Flood, J. Marmaro, W. Giusti, and K. Deetz. 1995a. Oligonucleotides with fluorescent dyes at opposite ends provide a quenched probe system useful for detecting PCR product and nucleic acid hybridization. PCR Methods Applic. 4: 357-362.

Livak, K.J., J. Marmaro, and J.A. Todd. 1995b. Towards fully automated genome-wide polymorphism screening. Nature Genet. 9: 341-342.

McCulloch, R.K., C.S. Choong, and D.M. Hurley. 1995. An evaluation of type and size for use in the determination of mRNA by competitive PCR. PCR Methods Applic. 4: 219-226.
Mullis, K., F. Faloona, S. Scharf, R. Saiki, G. Horn, and H. Erlich. 1986. Specific enzymatic amplification of DNA in vitro: the polymerase chain reaction. Cold Spring Harb. Symp. Quant. Biol. 51: 263-273.

Piatak, M.J., K.C. Luk, B. Williams, and J.D. Lifson. 1993. Quantitative competitive polymerase chain reaction for accurate quantitation of HIV DNA and RNA species. BioTechniques 14: 70-81.

Raeymaekers, L. 1995. A commentary on the practical applications of competitive PCR. Genome Res. 5: 91-94.

Siebert, P.D. and J.W. Larrick. 1992. Competitive PCR. Nature 359: 557-558.

Stoflet, E.S., D.D. Koeberl, G. Sarkar, and S.S. Sommer. 1988. Genomic amplification with transcript sequencing. Science 239: 491-494.

Received June 19, 1996; accepted in revised form August 16, 1996. 


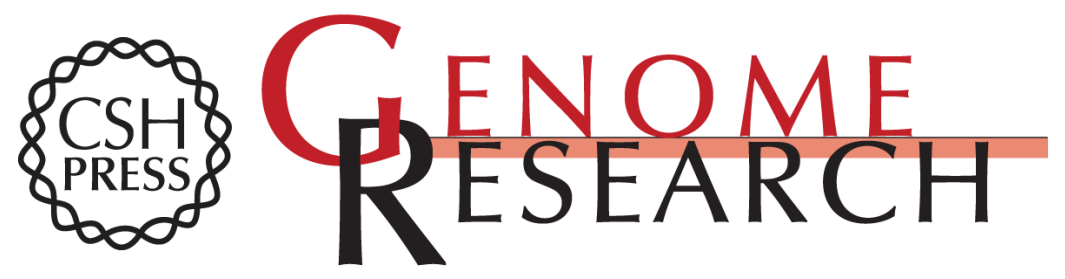

\title{
A novel method for real time quantitative RT-PCR.
}

\author{
U E Gibson, C A Heid and P M Williams
}

Genome Res. 1996 6: 995-1001

Access the most recent version at doi:10.1101/gr.6.10.995

References This article cites 13 articles, 4 of which can be accessed free at:

http://genome.cshlp.org/content/6/10/995.full.html\#ref-list-1

\section{License}

Email Alerting Receive free email alerts when new articles cite this article - sign up in the box at the Service top right corner of the article or click here.

\section{Affordable, Accurate Sequencing.}

To subscribe to Genome Research go to: https://genome.cshlp.org/subscriptions 